Org Lett. 2021 March 05; 23(5): 1648-1652. doi:10.1021/acs.orglett.1c00068.

\title{
Chemical exchanges between multilateral symbionts
}

\author{
Munhyung Bae ${ }^{\dagger}$, Emily Mevers ${ }^{\dagger}$, Gleb Pishchany ${ }^{\dagger}$, Sarah G. Whaley ${ }^{\ddagger}$, Charles O. Rock ${ }^{\ddagger}$, \\ David R. Andes $\S$, Cameron R. Currie ${ }^{\wedge}$, Monica T. Pupo", Jon Clardy ${ }^{\star},{ }^{*}$ \\ tDepartment of Biological Chemistry and Molecular Pharmacology, Harvard Medical School, \\ Boston, MA 02115, USA. \\ ‡Department of Infectious Diseases, St. Jude Children's Research Hospital, Memphis, TN 38105, \\ USA.
}

§Department of Medicine, University of Wisconsin School of Medicine and Public Health, Madison, WI 53705, USA.

^Department of Bacteriology, University of Wisconsin-Madison, Madison, WI 53706, USA.

"School of Pharmaceutical Sciences of Ribeirão Preto, University of São Paulo, Ribeirão Preto, SP, 14040-903, Brazil.

\section{Abstract}

Herein is a report on the molecular exchange occurring between multilateral symbiosis partners - a tit-for-tat exchange that led to the characterization of two new metabolites, conocandin B (fungal-derived) and dentigerumycin F (bacterial-derived). The structures were determined by NMR, mass spectrometry, genomic analysis, and chemical derivatizations. Conocandin B exhibits antimicrobial activity against both the bacterial symbionts of fungus-growing ant and human pathogenic strains by selectively inhibiting $\mathrm{FabH}$, thus disrupting fatty acid biosynthesis.

\section{Graphical Abstract}

\footnotetext{
"Corresponding Author Tel: +1-617-432-2845. Fax: +1-617-432-6424. jon_clardy@hms.harvard.edu. Author Contributions

M.B., E.M, G.P., and S.G.W. performed the experiments. M.B., E.M., and J.C. wrote the manuscript. J.C., C.O.R., D.R.A., C.R.C., and M.T.P. guided the study. All authors read, revised, and approved the manuscript.

Supporting Information

The Supporting Information is available free of charge on the ACS Publications website.

NMR spectra, images of the binary assays, MS chromatograms, putative functions of genes in the dentigerumycin F biosynthetic gene cluster, primers used in $S$. aureus overexpression constructs, and detailed experimental method (PDF).
} 


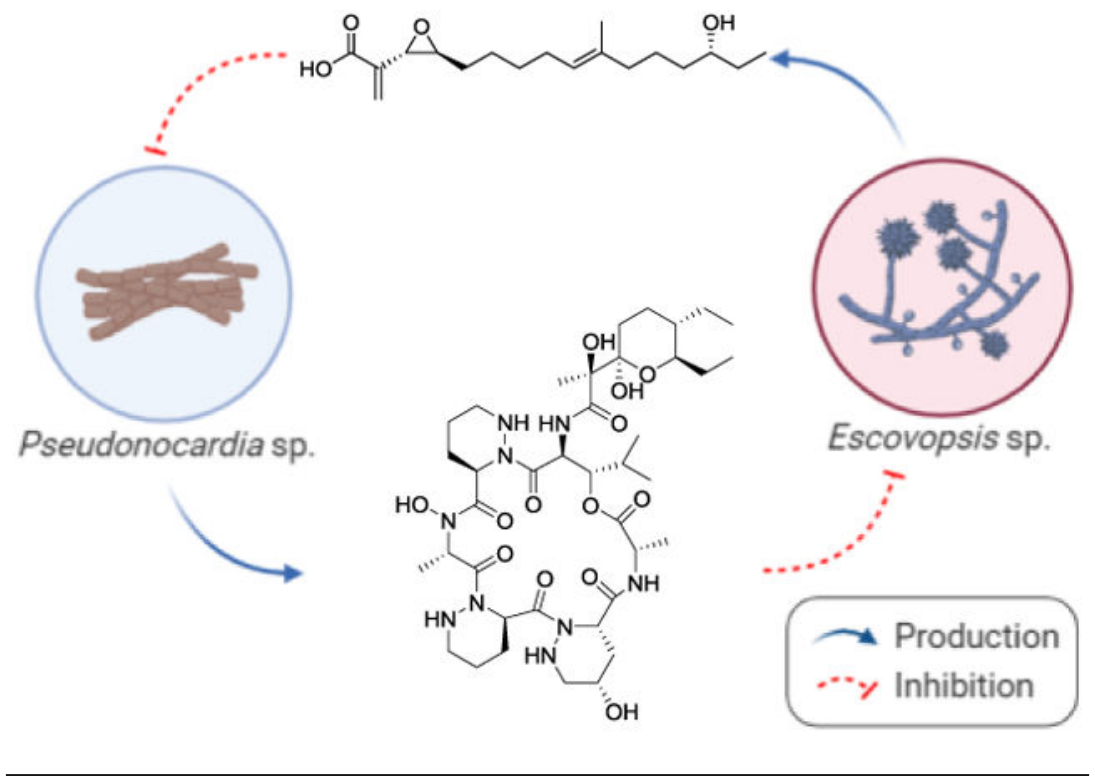

Chemists have studied naturally occurring small molecules before the concepts of molecule or function existed, and the studies have grown along with the science. These molecules fascinate chemists for their complex architectures; however, the study of what these molecules do for their producers have been less frequently explored.

A particularly informative system is that of the chemical ecology that regulates the microbial symbionts found in the nests of fungus-growing ants. ${ }^{1-6}$ These nests house fungal gardens in which plant material is brought to the nest by foraging ants deposited and converted into the food that feeds the colony. ${ }^{7-9}$ This beneficial ant-fungus relationship is threatened by specialized fungal pathogens that can overwhelm the gardens and eliminate the nest. ${ }^{10,11}$ In response to this existential threat, the ants have evolved specialized crypts on their exoskeleton to harbor symbiotic bacteria that produce chemical defenses to control the fungal pathogens. ${ }^{12,13}$ In return for producing chemical defenses, the ant host provides the symbiotic bacteria with essential nutrients. ${ }^{14}$ Our previous studies focused on the molecular diversity of the antifungal agents produced by the bacterial symbionts, ${ }^{6,15-17}$ but in this study, we sought to examine how specialization is reflected in the small molecule exchanges between the fungal pathogen and bacterial symbiont.

We focused, after some experimentation, on a single ant nest, a Trachymyrmex sp. nest designated ICBG2300 that was collected in the Adolpho Ducke Forest Reserve in the Amazon region of Brazil in 2017. The bacterial isolate from the nest, Pseudonocardia sp. ICBG1122 (Ps1122), is matched with the pathogenic fungus, Escovopsis sp. ICBG729 (Es729) from the same nest (Table S2,3). In order to study the symbiosis in a format that was both faithful to the natural relationship but amenable to efficient bioassay-guided fractionation, we used a trans-well assay system (Fig. S1, Table S4). ${ }^{18}$ Our study revealed two previously unreported molecules: dentigerumycin F (1) from Ps1122, which inhibits the growth of Es729; and conocandin B (2) from Es729, which inhibits the growth of Ps1122. Further, conocandin B induces the production of dentigerumycin F, and dentigerumycin 
F induces the production of conocandin B - a fully articulated example of a molecular tit-for-tat strategy (Fig. S2-4).

When Ps1122 was exposed to the supernatant of Es729, one particular Ps1122 metabolite was strongly upregulated. Analysis of this peak using high-resolution mass spectrometry (HRMS), MS/MS fragmentation patterns, and UV spectral data revealed that the induced metabolite was a member of the dentigerumycin family, a highly modified cyclic peptide that exhibits antifungal properties. ${ }^{2}$ The dentigerumycins have been isolated from antassociated Pseudonocardia sp. strains throughout the neotropics - Costa Rica, Panama, and Brazil - and they had been identified as the chemical defenses that protected the ant nests from Escovopsis sp. infections. ${ }^{5,6}$ The molecular formula of the induced metabolite, as determined by HR-ESI-qTOFMS data $\left([\mathrm{M}+\mathrm{H}]^{+} \mathrm{m} / \mathrm{z}\right.$ 868.4786), did not match any of the previously reported dentigerumycin analogs, but only differed by the loss of one methylene unit from dentigerumycin. NMR analysis (COSY, TOCSY, HSQC, and HMBC) confirmed this suggestion by identifying dentigerumycin $\mathrm{F}(\mathbf{1})$ differing from dentigerumycin by the loss of an aliphatic chain methylene (Fig. 1, Table S5,6 and Fig. S7-12). The results from the ROESY (Fig. S13), J-based (Fig. S14), and Marfey's analyses, along with the identified biosynthetic gene cluster (BGC) exhibiting 99\% similarity to known dentigerumycin BGCs (Fig. S15 and Table S7), strongly supports both the amino acid sequence and assigned stereochemistry to be consistent with dentigerumycin. Induced concentrations of $\mathbf{1}$ reach 46 $\mu \mathrm{M}$ when grown with the spent supernatant of Es729 and this is well above the concentration needed to inhibit the growth of Es729 (MIC $-8 \mu \mathrm{g} / \mathrm{mL}$; Fig. S5).

Addition of dentigerumycin F (1) to Es729 cultures at a sub-lethal concentration (5 $\mu \mathrm{g} / \mathrm{mL}$ ) significantly upregulated the production of two metabolites that could be visualized by their extracted molecular ions (Fig. S6). The two compounds are structural isomers with molecular ions of $311.2235 \mathrm{amu}$. As the two compounds could not be identified using various databases, a more traditional mass-guided purification scheme was initiated. Conocandin B (2) was isolated as amorphous powder having molecular formula of $\mathrm{C}_{18} \mathrm{H}_{30} \mathrm{O}_{4}$ determined by HR-ESI-qTOFMS analysis. ${ }^{1} \mathrm{H}$ NMR data for the compound revealed an allylic methyl, three oxygenated methines, two of which had the characteristic chemical shifts of an epoxide $\left(\delta_{\mathrm{H}} 3.52\right.$ and 2.65$)$, an vinylic hydrogen $\left(\delta_{\mathrm{H}} 5.14\right)$, an exomethylene ( $\delta_{\mathrm{H}} 5.80$ and 5.31), and a large aliphatic $\mathrm{CH}_{2}$ envelope $\left(\delta_{\mathrm{H}} 1.58-1.30\right)$. The ${ }^{13} \mathrm{C}$ NMR spectrum displayed corresponding features and, in addition, an ester carbonyl $\left(\delta_{\mathrm{C}}\right.$ 174.4), along with two quaternary olefinic carbons $\left(\delta_{\mathrm{C}} 146.4\right.$ and 136.6).

Comprehensive analysis of 2D NMR spectra (COSY, HSQC, HMBC, and ROESY) of 2 established the backbone to consist of an 18-membered fatty acid, but with a high degree of post-modifications (Fig. 2a, Table S8, Fig. S16-21). Key COSY and HMBC correlations established two partial structures. COSY correlations from the oxygenated methine (H-14; $\left.\delta_{\mathrm{H}} 3.43\right)$ to several aliphatic methylenes $-\mathrm{H}-15\left(\delta_{\mathrm{H}} 1.48\right.$ and 1.39$), \mathrm{H}-13\left(\delta_{\mathrm{H}} 1.43\right.$ and $1.30), \mathrm{H}-12\left(\delta_{\mathrm{H}} 1.58\right.$ and 1.45$)$, and $\mathrm{H}-11\left(\delta_{\mathrm{H}} 2.01\right.$ and 1.98$)$ - and the terminal methyl $\mathrm{H}-16\left(\delta_{\mathrm{H}} 0.92\right)$, led to the assignment of the first partial structure as a hexane chain bearing a branch hydroxyl group. Additional COSY correlations between the triplet olefinic proton, $\mathrm{H}-9\left(\delta_{\mathrm{H}} 5.14\right)$, and consecutive aliphatic protons from $\mathrm{H}-8$ to $\mathrm{H}-5\left(\delta_{\mathrm{H}} 1.72\right.$ and 1.70$)$ resulted in the expansion of an unmodified fatty acid aliphatic chain. The characteristic 
features of an epoxide, $\mathrm{H}-3\left(\delta_{\mathrm{H}} 3.52\right)$ and $\mathrm{H}-4\left(\delta_{\mathrm{H}} 2.65\right)$, were connected to the aliphatic chain at $\mathrm{C}-5$ by a COSY correlation between $\mathrm{H}-4$ and $\mathrm{H}-5$. Finally, the characteristic protons of an exomethylene, H-2' $\left(\delta_{\mathrm{H}} 5.80\right.$ and 5.31), exhibited a COSY correlation with $\mathrm{H}-3$ and a HMBC correlation to both $\mathrm{C}-2\left(\delta_{\mathrm{C}} 146.4\right)$ and $\mathrm{C}-1\left(\delta_{\mathrm{C}} 174.4\right)$, thus establishing a second partial structure as a fatty acid chain composed of 10 carbons bearing an epoxide ring and an exomethylene. Connection of the two partial structures was possible using key HMBC correlations from the singlet methyl group $\mathrm{H}-10^{\prime}\left(\delta_{\mathrm{H}} 1.59\right)$ to the quaternary carbon $\mathrm{C}-10$ $\left(\delta_{\mathrm{C}} 136.6\right), \mathrm{C}-9\left(\delta_{\mathrm{C}} 126.3\right)$, and $\mathrm{C}-11\left(\delta_{\mathrm{C}} 41.3\right)$, and completing the assignment of the planar structure of conocandin B (2) as shown in figure 1.

The relative configuration of $\mathbf{2}$ was established using $J$-based methods, ROE analysis, and optical rotation data. The small ${ }^{3} \mathrm{~J}_{\mathrm{HH}}$ coupling $(2.0 \mathrm{~Hz})$ between $\mathrm{H}-3$ and $\mathrm{H}-4$ suggests that the epoxide is of the trans configuration, and this was supported by the key ROESY correlation between the same protons. The absolute stereochemistry was assigned by comparing the $[a]_{D}$ data of $\mathbf{2}$ to published data of related analogs, which established the assignment as $3 S$ and $4 S$ (See methods; Fig. S22). ${ }^{19}$ The final stereocenter, the isolated hydroxyl, posed much greater challenges. Using a modified Mosher's method - dichloromethane as the solvent instead of pyridine - allowed for the successful derivatization of 2 while limiting degradation and the stereocenter was determined to be $14 S$ (Fig. 2b, Fig. S29-32, and Table S10). ${ }^{20}$ Thus, establishing the absolute stereoassignments of conocandin B as $3 S, 4 S$, and $14 S$.

The remaining structural isomer had an identical UV spectrum, however based on ${ }^{1} \mathrm{H}$ NMR data it was evident that conocandin C (3) lacked both the epoxide and exomethylene functionality. Comprehensive analysis of the NMR spectroscopic data (Table S9 and Fig. S23-28) revealed that the epoxide protons were replaced by signals at $\delta_{\mathrm{H}} 4.26$ and 4.11 and the exomethylene signals were replaced with a doublet methyl. Furthermore, $\mathrm{HMBC}$ correlations from $\mathrm{H}-4\left(\delta_{\mathrm{H}} 4.26\right)$ to $\mathrm{C}-1\left(\delta_{\mathrm{C}} 181.6\right)$ established the presence of a heterocyclic lactone ring in $\mathbf{3}$. The hydroxyl group at $\mathrm{C}-14$ in $\mathbf{2}$ has been oxidized to a ketone $\left(\delta_{\mathrm{C}} 215.0\right)$, yielding the planar structure of $\mathbf{3}$ as shown in figure 1 . The relative and absolute configuration of the heterocyclic lactone ring was determined using similar methods described above. The coupling between $\mathrm{H}-3$ and $\mathrm{H}-4$ was $5.5 \mathrm{~Hz}$ indicating a trans orientation and a key NOESY correlation between 2-Me and H-4 allowed for the relative assignment of the 5-membered lactone ring as $2 R^{*}, 3 S^{*}$, and $4 R^{*}$ (Fig. 2a). Using the Mosher's method ${ }^{20}$ to derivatize the secondary hydroxy on C-3 allowed for the assignment of the absolute stereochemistry of $\mathbf{3}$ as $2 R, 3 S$, and $4 R$ (Fig. 2c, Fig. S33-36, and Table S11).

Initial spot-on-lawn inhibitory assays against Ps1122 revealed that only conocandin B (2) possessed significant antimicrobial activity, while conocandin C (3) did not produce a visible zone of inhibition at concentrations up to $100 \mu \mathrm{g} / \mathrm{mL}$. This suggests that the reactive epoxide functionality is an essential feature for antibacterial activity. Conocandin $\mathrm{B}$ exhibited minimum inhibitory concentrations (MICs) ranging from $0.5-2 \mu \mathrm{g} / \mathrm{mL}$ (Fig. 3a) against four Pseudonocardia sp. strains that were isolated in Brazil and Panama. Compound 2 was also evaluated against various human bacterial pathogens, including gram positive bacteria ( $S$. aureus, MRSA, and VRE) and gram negative bacteria (Klebsiella salmonella, Enterococcus coli, and Pseudomonas aeruginosa). Conocandin B possesses potent activity 
against gram positive pathogens with MICs between $0.5-10 \mu \mathrm{g} / \mathrm{mL}$ but was ineffective against gram negative pathogens (Fig. 3a and Fig. S37). Compound 2 was also evaluated against fungus-growing ant's crop fungus and various fungal pathogens, however it did not exhibit any inhibitory activity against any of the fungal strains (Fig. S38).

Conocandin B loosely resembles the structure of cerulenin, an epoxide-containing C-12 fatty acid antibiotic as a fungal metabolite, and amycomicin, an epoxy-isonitrile containing C-18 fatty acid with potent activity against $S$. aureus. Both of these metabolites are known fatty acid synthase inhibitors, ${ }^{18,21}$ although cerulenin also inhibits sterol biosynthesis. ${ }^{22}$ Therefore, we suspect that $\mathbf{2}$ may have a similar target. Screening $\mathbf{2}$ against a panel of $S$. aureus strains each possessing overexpression of different steps within fatty acid biosynthesis suggested that it was also targeting 3-ketoacyl-[acyl-carrier-protein] synthase 3 (FabH) as its MIC was increased 5-fold (Fig. 3b). ${ }^{23-26}$ FabH initiates bacterial fatty acid synthesis by condensing branched-chain acyl-CoA derived from amino acid metabolism with malonyl-ACP to form ketoacyl-ACP. To further establish FabH as a target, $\mathbf{2}$ was tested in a FabH enzyme radiochemical assay. In this assay, the activity of purified FabH from $S$. aureus and $B$. subtilis is determined by calculating how much $\left[{ }^{14} \mathrm{C}\right]-$ ketoacyl-ACP is formed. Conocandin B inhibited the activity of both the $S$. aureus $\mathrm{FabH}$ and B. subtilis FabH at $\mathrm{IC}_{50}$ of $18.8 \pm 2.5 \mu \mathrm{M}$ and $53.5 \pm 10.4 \mu \mathrm{M}$, respectively (Fig. S39).

Dentigerumycin $\mathrm{F}$ and conocandin B were each evaluated in in vivo mouse models of infections using $C$. albicans $\mathrm{K} 1$ and methicillin-resistant $S$. aureus, respectively. Dentigerumycin F exhibited significant decrease of fungal colony forming units (CFU) in the kidney in dose-dependent fashion when compared to untreated mice (Fig. S40). Conocandin B exhibited potent in vitro efficacy, but only showed a modest decrease in CFU loads in the kidney in the in vivo model. We believe this discrepancy is due to stability liabilities.

Previous studies for fungus-growing ant's symbiosis have focused on antifungal agents derived from Pseudonocardia sp., including highly-modified cyclic peptide dentigerumycins, ${ }^{2,5,6}$ glycosylated indolocarbazole rebeccamycin, ${ }^{3}$ and macrocyclic polyene selvamicin. ${ }^{4}$ However, very few studies have analyzed the metabolites produced by the specific parasitic fungal pathogen of the ant's society. ${ }^{27}$ In this study, we used the trans-well system to unravel the intimate and specialized chemical interaction occurring between Pseudonocardia sp. and Escovopsis sp. that shared the same nest. Activation of cryptic chemical defenses by replicating environmental conditions led to the identification of three new metabolites - dentigerumycin F, conocandin B and $\mathrm{C}$ - each possessing toxic activity against the producer of the other metabolite. Their reciprocal activities, reciprocal induction, and limited distribution of both molecules argue that both the metabolites, their regulation, and their activities have co-evolved over a lengthy interaction.

\section{Supplementary Material}

Refer to Web version on PubMed Central for supplementary material. 


\section{ACKNOWLEDGMENT}

This work was funded by National Institutes of Health grants (U19 AI42720 and U19 TW009872) and R01 GM03496 (C.O.R.), and the American Lebenese Syrian Associated Charities. The content is solely the responsibility of the authors and does not necessarily represent the official views of the National Institutes of Health. We thank the Harvard Medical School's Analytical Chemistry Core (ACC), East Quad NMR facility, and Institute of Chemistry and Cell Biology (ICCB) facility for their analytical services. And we thank the Duke University School of Medicine for the use of the Sequencing and Genomic Technologies Shared Resource, which provided PacBio sequencing service.

\section{REFERENCES}

(1). Mevers E, Saurí J, Liu Y, Moser A, Ramadhar TR, Varlan M, Williamson RT, Martin GE, Clardy J. Homodimericin A: A Complex Hexacyclic Fungal Metabolite. J. Am. Soc2016; 138: 1232412327.

(2). Oh D-C, Poulsen M, Currie CR, Clardy J. Dentigerumycin: a bacterial mediator of an ant-fungus symbiosis. Nat. Chem. Biol2009; 5: 391-393. [PubMed: 19330011]

(3). Van Arnam EB, Ruzzini AC, Sit CS, Currie CR, Clardy J. A Rebeccamycin Analog Provides Plasmid-Encoded Niche Defense. J. Am. Soc2015; 137: 14272-14274.

(4). Van Arnam EB, Ruzzini AC, Sit CS, Horn H, Pinto-Thomás AA, Currie CR, Clardy J. Selvamicin, an atypical antifungal polyene from two alternative genomic contexts. Proc. Natl. Acad. Sci. USA2016; 113: 12940-12945. [PubMed: 27803316]

(5). Sit CS, Ruzzini AC, Van Arnam EB, Ramadhar TR, Currie CR, Clardy J. Variable genetic architectures produce virtually identical molecules in bacterial symbionts of fungus-growing ants. Proc. Natl. Acad. Sci. USA2015; 112; 13150-13154. [PubMed: 26438860]

(6). Wyche TP, Ruzzini AC, Beemelmanns C, Kim KH, Klassen JL, Cao S, Poulsen M, Bugni TS, Currie CR, Clardy J. Linear peptides are the major products of a biosynthetic pathway that encodes for cyclic depsipeptides. Org. Lett2017; 19: 1772-1775. [PubMed: 28326787]

(7). Weber NFungus-growing Ants. Science1966; 121: 587-604.

(8). Chapela IH, Rehner SA, Schultz TR, Mueller UG. Evolutionary History of the Symbiosis Between Fungus-Growing Ants and Their Fungi. Science1994; 266: 1691-1694. [PubMed: 17775630]

(9). Mueller UG, Rehner SA, Schultz TR. The Evolution of Agriculture in Ants. Science1998; 281: 2034-2038. [PubMed: 9748164]

(10). Currie CR, Stuart AE. Weeding and grooming of pathogens in agriculture by ants. Proc. Biol. Sci2001; 268: 1033-1039. [PubMed: 11375087]

(11). Currie CR, Mueller UG, Malloch D. The agricultural pathology of ant fungus gardens. Proc. Natl. Acad. Sci. USA1999; 96: 7998-8002. [PubMed: 10393936]

(12). Currie CR, Scott JA, Summerbell RC, Malloch D. Fungus-growing ants use antibiotic-producing bacteria to control garden pests. Nature 1999; 398: 701-704.

(13). Currie CR, Poulsen M, Mendenhall J, Boomsma JJ, Billen J. Coevolved Crypts and Exocrine Glands Support Mutualistic Bacteria in Fungus-Growing Ants. Science2006; 311: 81-83. [PubMed: 16400148]

(14). Steffan SA, Chikaraishi Y, Currie CR, Horn H, Gaines-Day HR, Pauli JN, Zalapa JE, Ohkouchi N. Microbes Are Trophic Analogs of Animals. Proc. Natl. Acad. Sci. USA2015; 112: 1511915124. [PubMed: 26598691]

(15). Puri AW, Mevers E, Ramadhar TR, Petras D, Liu D, Piel J, Dorrestein PC, Greenberg EP, Lidstrom ME, Clardy J. Tundrenone: An Atypical Secondary Metabolite from Bacteria with Highly Restricted Primary Metabolism. J. Am. Chem. Soc2018; 140: 2002-2006. [PubMed: 29361220]

(16). Wyche TP, Ruzzini AC, Schwab L, Currie CR, Clardy J. Tryptorubin A: A Polycyclic Peptide from a Fungus-Derived Streptomycete. J. Am. Chem. Soc2017; 139: 12899-12902. [PubMed: 28853867]

(17). Cantley AM, Woznica A, Beemelmanns C, King N, Clardy J. Isolation and Synthesis of a Bacterially Produced Inhibitor of Rosette Development in Choanoflagellates. J. Am. Soc2016; 138: 4326-4329. 
(18). Pishchany G, Mevers E, Ndousse-Fetter S, Horvath DJ, Paludo CR, Silva-Junior EA, Koren S, Skaar EP, Clardy J, Kolter R. Amycomicin is a potent and specific antibiotic discovered with a targeted interaction screen. Proc. Natl. Acad. Sci. USA2018: 115; 10124-10129. [PubMed: 30228116]

(19). Müller JM, Fuhrer H, Gruner J, Voser W. Metabolites From Microorganisms. Conocandin, a New Fungi-Static Antibiotic. Helv. Chim. Acta1976; 59: 2506-2514. [PubMed: 1017972]

(20). Seco JM, Quiñoá E, Riguera R. A Practical Guide for the Assignment of the Absolute Configuration of Alcohols, Amines, and Carboxylic Acids by NMR. Tetrahedron: Asymmetry2001; 12: 2915-2925.

(21). Vance D, Goldberg I, Mitsuhashi O, Bloch K, Ōmura S, Nomura S. Inhibition of Fatty Acid Synthetases by the Antibiotic Cerulenin. Biochem. Biophys. Res. Commun1972; 48: 649-656. [PubMed: 4625866]

(22). Nomura S, Horiuchi T, Ōmura S. Inhibition of sterol and fatty acid biosyntheses by cerulenin in cell-free systems of yeast. J. Antibiot1972; 25: 365-368.

(23). Rine J, Hansen W, Hardeman E, Davis RW. Targeted selection of recombinant clones through gene dosage effects. Proc. Natl. Acad. Sci. USA1983; 80: 6750-6754. [PubMed: 6316322]

(24). Banerjee A, Dubnau E, Quemard A, Balasubramanian V, Um KS, Wilson T, Collins D, de Lisle G, Jacobs WR. inhA, a gene encoding a target for isoniazid and ethionamide in Mycobacterium tuberculosis. Science1994; 263: 227-230. [PubMed: 8284673]

(25). Sugden CJ, Roper JR, Williams JG. Engineered gene over-expression as a method of drug target identification. Biochem. Biophys. Res. Commun2005; 334: 555-560. [PubMed: 16005849]

(26). Shi W, Zhang X, Jiang X, Yuan H, Lee JS, Barry CE, Wang H, Zhang W, Zhang Y. Pyrazinamide Inhibits Trans-Translation in Mycobacterium Tuberculosis. Science2011; 333: 1630-1632. [PubMed: 21835980]

(27)(a). Heine D, Holmes NA, Worsley SF, Santos ACA, Innocent TM, Scherlach K, Patrick EH, Yu DW, Murrell JC, Vieria PC, Boomsma JJ, Hertweck C, Hutchings MI, Wilkinson B. Chemical Warfare Between Leafcutter Ant Symbionts and a Co-Evolved Pathogen. Nat. Comm2018; 9: 1-11.(b)Dhodary B, Schilg M, Wirth R, Spiteller D. Secondary Metabolites from Escovopsis weberi and Their Role in Attacking the Garden Fungus of Leaf-Cutting Ants. Chem. Eur. J2018; 24: 4445-4452. [PubMed: 29356159]

Org Lett. Author manuscript; available in PMC 2021 September 26. 

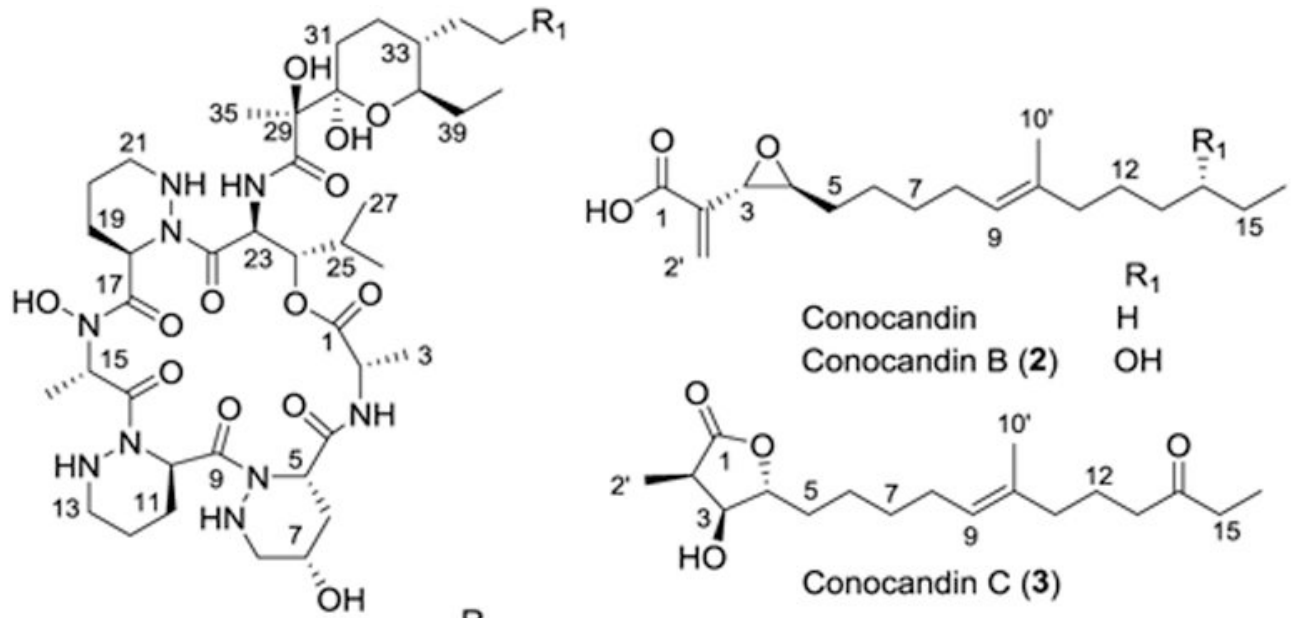

Dentigerumycin

$\mathrm{CH}_{3}$

Dentigerumycin F (1)

$\mathrm{H}$

Figure 1.

Chemical structures of the isolated dentigerumycins and conocandins. 
a
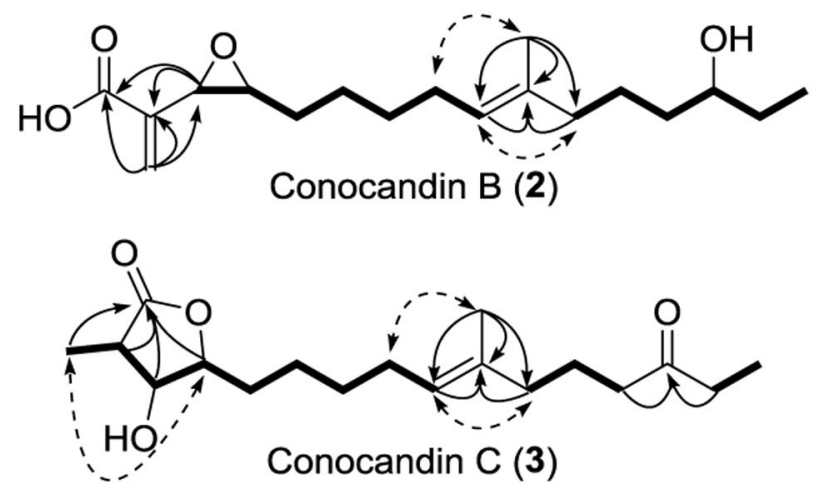

- COSY/TOCSY

$\frown \mathrm{HMBC} \quad \boldsymbol{r}^{-} \mathrm{Y}$ ROESY

b

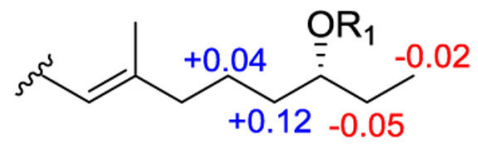

$\mathrm{R}_{1}$
C

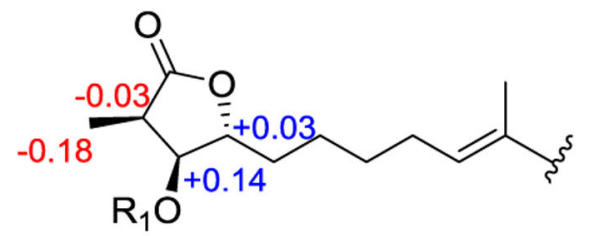

$\mathrm{R}_{1}$

Conocandin B S-MTPA ester (4) Conocandin C S-MTPA ester (6)

Conocandin B R-MTPA ester (5) Conocandin C R-MTPA ester (7)

Figure 2. Structural characterization of conocandin $B$ and $C$.

a. Key 2D NMR correlations for conocandin B and C ( 2 and $\mathbf{3})$. b. $\Delta_{S-R}$ values of MTPA ester (4 and $\mathbf{5})$ of conocandin B. c. $\Delta_{S-R}$ values of MTPA ester (6 and 7) of conocandin C.

Org Lett. Author manuscript; available in PMC 2021 September 26. 


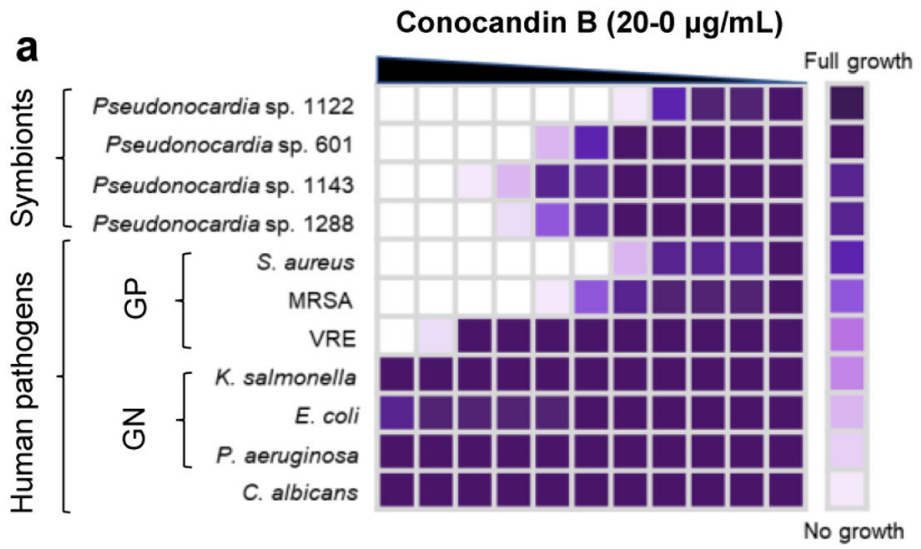

b

fab gene mutant assay

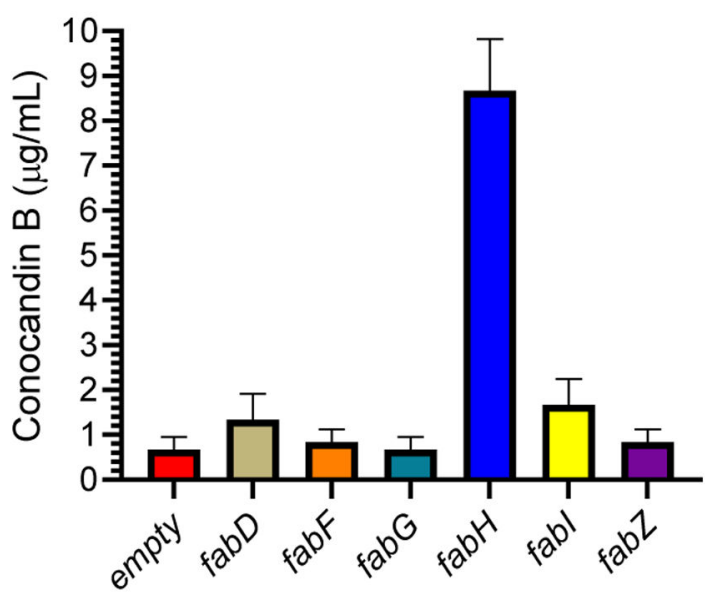

Figure 3. Antibacterial activity and mechanism of action of conocandin B.

a. MIC values for conocandin B against Pseudonocardia strains and select human pathogens. Abbreviations are as follow: GP, gram positive; and GN, gram negative. b. MIC values for conocandin B against strains of $S$. aureus that overexpress individual fatty acid biosynthetic genes. 